\title{
Gentiopicroside (GENT) protects against sepsis induced by lipopolysaccharide (LPS) through the NF-kB signaling pathway
}

\author{
Qiong Wang ${ }^{1,2 \#}$, Xin Zhou ${ }^{3,4 \#}$, Long Yang ${ }^{5 \#}$, Maocai Luo ${ }^{6}$, Lei Han ${ }^{3,4}$, Yao Lu ${ }^{3,4}$, Qi Shi ${ }^{1,2}$, Yongjun Wang ${ }^{1,2}$, \\ Qianqian Liang ${ }^{1,2}$
}

${ }^{1}$ Institute of Spine, Longhua Hospital, Shanghai University of Traditional Chinese Medicine, Shanghai 200032, China; ${ }^{2}$ Key Laboratory of theory and Theory and Therapy of Muscles and Bones, Ministry of Education, Shanghai University of Traditional Chinese Medicine, Shanghai 200032, China; ${ }^{3}$ Shanghai Institute of Biochemistry and Cell Biology CAS, Shanghai 200031, China; ${ }^{4}$ Institute of Biochemistry and Cell Biology, Shanghai Institutes for Biological Sciences, Chinese Academy of Sciences, Shanghai 200031, China; ${ }^{5}$ Department of Rehabilitation Medicine, Shanghai Eighth People's Hospital, Shanghai 200235, China; 'Department of Pediatrics, Ruijin hospital, Shanghai Jiaotong University School of Medicine, Shanghai 200025, China

Contributions: (I) Conception and design: Q Liang; (II) Administrative support: None; (III) Provision of study materials or patients: M Luo, L Han, L Yang; (IV) Collection and assembly of data: Q Wang, X Zhou, L Yang; (V) Data analysis and interpretation: Q Wang, X Zhou, L Yang; (VI) Manuscript writing: All authors; (VII) Final approval of manuscript: All authors.

\#These authors contributed equally to this work.

Correspondence to: Yongjun Wang; Qianqian Liang. Institute of Spine, Longhua Hospital, Shanghai University of Traditional Chinese Medicine, 725 Wan-Ping South Road, Shanghai 200032, China. Email: yjwang88@hotmail.com; liangqianqiantcm@126.com.

Background: Sepsis is a high-mortality disease without effective therapeutic options. The hyperactivation of the monocyte-macrophage system, especially M1 macrophages, triggers the onset of septic shock. Gentiopicroside (GENT), the main active component in the traditional Chinese medicinal herb Radix Gentianae, has been shown to have anti-inflammatory properties. Nevertheless, this anti-inflammatory effect has not been fully elucidated.

Methods: In vitro, we stimulated primary bone marrow-derived macrophages (BMMs) or peritoneal elucidated macrophages (PEMs) by lipopolysaccharide (LPS) and interferon (IFN)- $\gamma$ and pre-treated with GENT and we tested the cytokines such as interleukin (IL)-1 $\beta$, IL-6 and tumor necrosis factor (TNF) $\alpha$ production by enzyme linked immunosorbent assay (ELISA) or real-time quantitative PCR (qPCR). Further, we determined the NF- $\mathrm{BB}$-mediated inflammatory pathway such as IKK $\alpha / \beta$ and $\mathrm{p} 65$ phosphorylation by Western blot. Then we detected the p65 nuclear localization by immunofluorescent staining. Moreover, $\mathrm{NF}-\kappa \mathrm{B}$ inhibitor and p65-targeted siRNAs were further used to validate the anti-inflammatory mechanism of GENT. In vivo, GENT (50 mg/kg) was administered intragastrically before and after LPS (40 mg/ $\mathrm{kg}$ ) injection. The death time were recorded and the serum levels of IL-1 $\beta$, IL- 6 and TNF $\alpha$ were tested by ELISA, and the IL-1 $\beta$, IL- 6 and TNF $\alpha$ mRNA expression in the lung were test by qPCR and the M1 infiltration in the lung were determined by F4/80 and INOS immunofluorescent staining

Results: In vitro, we observed that GENT reduced the inflammatory cytokine production of BMMs stimulated by (LPS)/IFN- $\gamma$ and ameliorated the phosphorylation of IKK $\alpha / \beta$ and $\mathrm{p} 65$, the degradation of $\mathrm{I} \kappa \mathrm{B} \alpha$, and the translocation of p65 into the nucleus. We did not find GENT has any effect on MAPK signaling under LPS/IFN- $\gamma$ stimulation. NF- $\mathrm{B}$ inhibitor and p65 siRNAs eliminated the inhibition effect of GENT. In vivo, we observed GENT prevented mice from dying in the LPS-induced shock model and decreased the serum levels of IL-1 $\beta$ and IL-6, the mRNA expression of IL-1 $\beta$, IL-6 and TNF $\alpha$ in lung tissue, and the amount of M1 macrophage infiltration in the lung.

Conclusions: GENT prevented LPS/IFN- $\gamma$-induced inflammatory cytokine production by macrophages through the NF- $\mathrm{kB}$ signaling pathway in vitro and protected against the endotoxin shock induced by LPS in vivo.

Keywords: Gentiopicroside (GENT); lipopolysaccharide shock (LPS shock); primary macrophages; NF-кB 
Submitted Jul 21, 2019. Accepted for publication Nov 08, 2019.

doi: 10.21037/atm.2019.11.126

View this article at: http://dx.doi.org/10.21037/atm.2019.11.126

\section{Introduction}

Sepsis is a life-threatening condition and has a high rate of mortality. Globally, sepsis is common, exhibiting an estimated population incidence of $270-535$ cases per 100,000 person-years and $25-30 \%$ in-hospital mortality (1-3). Despite advances in care, epidemiological studies suggest that sepsis remains a considerable problem around the world. In the United States, admissions for sepsis have overtaken those for myocardial infarction and stroke (4). Sepsis is the systemic inflammatory response to infection, and the endotoxin lipopolysaccharide (LPS) from Gramnegative bacteria and bacterial RNA or DNA are known to be potent stimuli of inflammatory responses via the toll-like receptors (TLRs) (5). Clinically, broad spectrum antimicrobials are strongly recommended as the first choice to manage sepsis (6). Nevertheless, the side effects of antibiotics, such as antibiotic resistance and kidney injury, have hampered the efforts of physicians to treat sepsis. Thus, new therapeutic agents for the treatment of sepsis are still urgently needed.

Innate immune cells, such as monocytes/macrophages, play a central role in the process of sepsis (7). There are two types of macrophages: those resulting from classical activation (M1) and alternative activation (M2). M1 macrophages are stimulated by LPS/interferon (IFN)- $\gamma$ or $\mathrm{TNF} \alpha / \mathrm{IFN}-\gamma$ and produce NOS, which is synthesized by inducible NO synthase (iNOS), causing a robust and essential inflammatory reaction, leading to extensive tissue damage and pathological manifestations (8), while M2 macrophages are stimulated by IL-4/13 and produce arginase (9). Generally, M1 polarized macrophages are involved in resistance to pathogens, while M2 polarized macrophages help to repair and remodel tissue, as well as resisting parasites and tumor growth (10). Previous studies found that in sepsis, high circulating concentrations of M1 polarized macrophages mean high mortality because M1 macrophages produce pro-inflammatory cytokines, such as interleukin (IL)-1 $\beta$, IL-6 and tumor necrosis factor (TNF)- $\alpha$, inflammatory mediators, such as nitric oxide (NO) synthesized by inducible NO synthase (iNOS), and chemokines, such as C-X-C motif chemokine (CXCL) 10, which contributes to cardiac failure, multiple organ failure and irreversible death (11-13). When macrophage surface binding proteins, such as TLRs, IFN- $\gamma$, and/or TNF $\alpha$, are activated, downstream cell signaling proteins, such as IKK $\alpha$ / $\beta$ (I $\kappa \alpha / \beta$ kinase), and enzymes in the mitogen-activated protein kinase (MAPK) cascade, including extracellular signal-regulated kinase (ERK), c-Jun N-terminal kinase (JNK), and p38 mitogen-activated protein kinases (p38), are activated. Among these proteins, when IKK $\alpha / \beta$ is activated, free NF- $\kappa \mathrm{B}$ translocates into the nucleus, binding to $\kappa \mathrm{B}$ target gene promoter sites and inducing the transcription of pro-inflammatory cytokines and mediators $(14,15)$. p65 (RelA), RelB, c-Rel, p50 and p105 are five members of the NF- $\kappa$ B family with an evolutionarily conserved Rel homology region, which can form heterodimers or homodimers $(16,17)$. Among these proteins, p65 is the classical NF- $\mathrm{\kappa B}$ family member possessing a transcription activation domain. It was widely accepted that small molecules inhibiting NF- $\mathrm{KB}$ activation might have therapeutic potential (18). If we could identify a means of inhibit the cytokine and chemokine production of M1 macrophages, we might achieve remission of sepsis induced by LPS and reduce deaths.

As a traditional medicine designed for its antiinflammation properties, Gentiana triflora and Radix Gentianae macrophyllae have been studied continuously (19-23). Gentiana scabra and Gentiana macrophylla Pall (also named Qinjiao in China) have been widely used for treating pain and inflammatory conditions, such as rheumatoid arthritis, diabetes, apoplexy, paralysis and stomachache in Chinese herbal medicine (24). Recently, it was reported that the root extract of Gentiana macrophylla Pall alleviated B19-NS1-exacerbated liver inflammation in NZB/W F1 mice by downregulating TNF- $\alpha / \mathrm{NF}-\kappa \mathrm{B}$ (p65) signaling (25). Gentiopicroside (GENT, the chemical structure is shown in Figure 1A), a secoiridoid glycoside, is one of the major active compounds of Gentiana scabra and Gentiana macrophylla Pall (26). GENT was reported to have anti-inflammatory activities, which could prevent an IL-1 $\beta$-induced inflammation response in chondrocytes (27), inhibit persistent inflammatory pain (28), exert antiinflammatory effects on experimental acute colitis (29) and pancreatitis (30), and protect against LPS-induced murine fulminant hepatic failure (22). However, the antiinflammatory effects of GENT on LPS-induced sepsis and 
LPS-stimulated macrophages have not been thoroughly characterized.

In the current study, we aimed to investigate the antiinflammatory effects and mechanisms of GENT in LPSstimulated mouse peritoneal macrophages and LPS-induced sepsis in mice.

\section{Methods}

\section{Experimental procedures}

Mice

C57BL6 mice were purchased from Shanghai Slac Laboratory Animal Co. Ltd. All animal protocols were approved by Longhua Hospital, Shanghai, China, and all methods were carried out in accordance with the relevant guidelines and regulations. All mice were fed in an IVC system under controlled temperature $\left(23^{\circ} \mathrm{C}\right)$ and light conditions (12 h light/12 h dark cycle) with ad libitum access to water and food. The procedure was conducted only after the mice were fed adaptively for at least one week.

\section{LPS shock model and GENT treatment}

For survival curve observation, twenty 7-8-week-old female C57BL6 mice (weight between 17 grams to 19 grams) were randomly divided into an LPS group $(\mathrm{n}=10)$ and a GENT group $(\mathrm{n}=10)$. After intraperitoneal (i.p.) injection of GENT (50 mg/kg, $2 \mathrm{mg} / \mathrm{mL}$ ) for GENT group or the same volume of physiological saline for the LPS group for 30 minutes, mice of both groups were treated with lethal LPS $(40 \mathrm{mg} / \mathrm{kg}$, $2 \mathrm{mg} / \mathrm{mL}$, i.p.) to induce LPS shock. Both LPS and GENT were dissolved in physiological saline. The mice were injected 8 times with GENT or saline every 2 hours after the first injection. All mice were closely observed, the time and number of deaths were recorded every hour and the survival rates were calculated. The experiment was replicated 3 times.

For serum and tissue investigation, a total of fifty 7-8-week-old female C57BL6 mice (weight between 17 grams to 19 grams ) were randomly divided into three groups, an LPS group $(n=20)$, a GENT group $(n=20)$ and a mock group $(\mathrm{n}=10)$. Firstly, the GENT group mice were injected with GENT (50 mg/kg, $2 \mathrm{mg} / \mathrm{mL}$ ), and the LPS and mock groups were injected with the same volume of physiological saline. Thirty minutes later, both LPS and GENT group mice received an injection of LPS at the same dosage mentioned above, while the mock group mice were injected with the same volume of saline as a negative control. Serum and lung tissue were collected at the indicated time points ( 2 hours and 4 hours after LPS injection) for cytokine measurements and morphological evaluation. GENT was purchased from Chemfaces (cat. \# CFN98047, CAS: 0831-76-9), and LPS from Escherichia coli O55:B5 was purchased from Sigma (cat. \# L2880) and dissolved in physiological saline.

\section{Cell preparation}

Primary bone marrow-derived macrophages (BMMs) were obtained from the bone marrow of 8-12-week-old C57BL6 mice. Briefly, bone marrow cells were collected from tibias and femur bones. Following red blood cell lysis, centrifugation and discarding of supernatant, bone marrow cells were seeded at 2 million/well in 12-well plates in complete 1640 medium (Invitrogen, Grand Island, CA, USA) containing $10 \%$ (vol/vol) fetal bovine serum (FBS), penicillin and streptomycin $(100 \mathrm{U} / \mathrm{mL})$ and $20 \mathrm{ng} / \mathrm{mL}$ murine M-CSF (Peprotech, cat. \# 315-02). Half of the medium was replaced with fresh medium at the third and fifth days. At the sixth day, the medium was fully changed with complete 1640 medium (without M-CSF), and the adherent cells were fully mature BMMs, which were used for subsequent experiments.

Primary mouse peritoneal elucidated macrophages (PEMs) from C57BL6 mice were prepared as described previously (5). Briefly, mice were injected intraperitoneally with $3 \mathrm{~mL}$ of $3 \%$ BBLTM Thioglycollate Medium Brewer Modified medium (BD Pharmingen, MD, USA; cat. \# 211716). Four days later, we obtained PEMs by repeatedly washing the peritoneal cavity with Dulbecco's Modified Eagle's medium (DMEM). The PEMs were cultured in complete DMEM supplemented with $10 \%$ (vol/vol) FBS, penicillin and streptomycin $(100 \mathrm{U} / \mathrm{mL})$.

RAW 264.7 cells (generous gifts from Dr. B. Sun, SIBCB, CAS, Shanghai, China) were used to test cell viability.

\section{siRNA transfection}

Lipofectamine ${ }^{\circledR}$ RNAiMAX Transfection Reagent was used to transfect $40 \mathrm{nM}$ synthesized siRNA or nonspecific siRNA (GenePharma) into PEMs according to the manufacturer's instructions. The sequences of two P65 siRNAs were AGAAGACAUUGAGGUGUAUTT (5'-3') (p65\#1) and GAAGAAGAGUCCUUUCAAUTT (5'-3') (p65\#2).

\section{RNA extraction and qPCR}

Total RNA was extracted from tissues or cells by TRIzol 
A<smiles>C=C[C@H]1C2=CCCC(=O)C2=CO[C@@H]1O[C@@H]1O[C@H](CCl)[C@@H](O)[C@H](O)[C@H]1O</smiles>

B

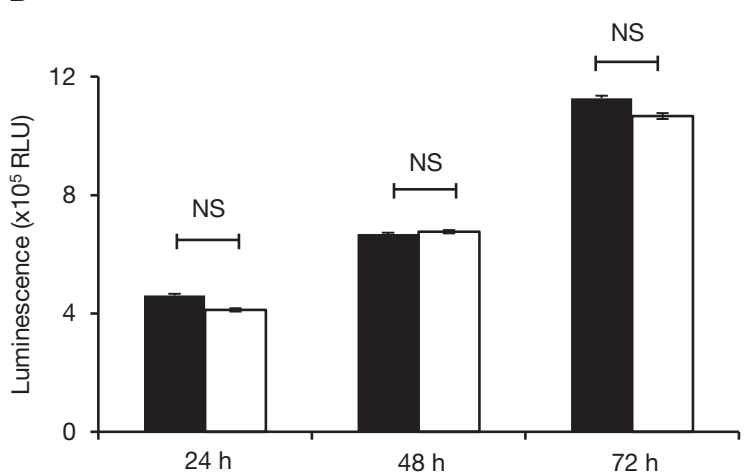

C

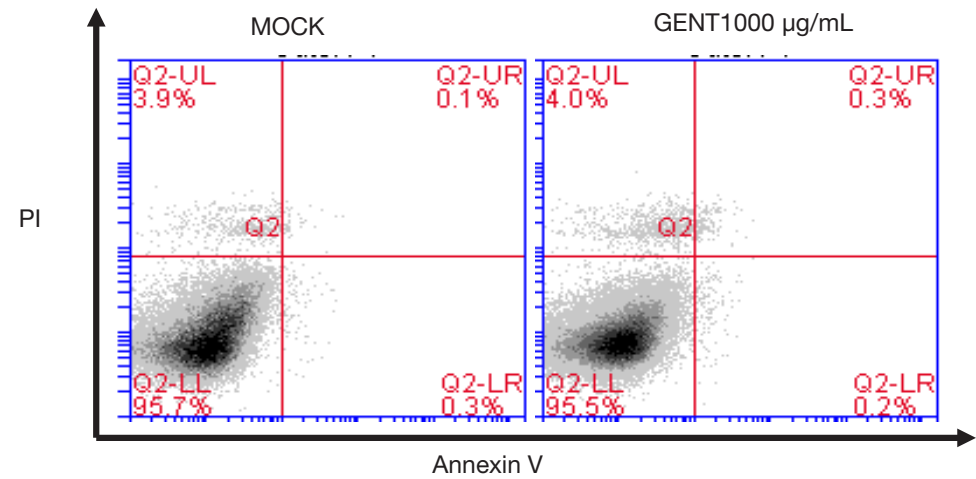

D

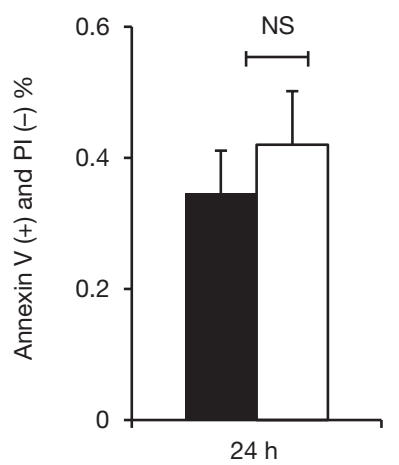

$\mathrm{E}$

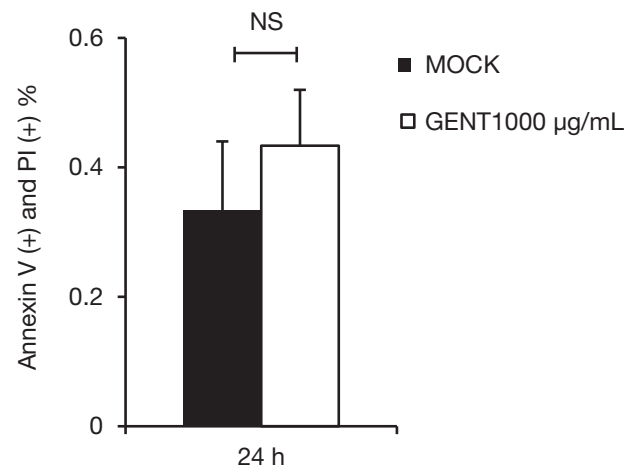

Figure 1 GENT had no cytotoxic effect. (A) GENT structure. (B) Raw 264.7 cells were treated with GENT (1,000 $\mu \mathrm{g} / \mathrm{mL})$ or the same volume of PBS for 24, 48 and 72 hours. Cell viability was determined by CellTiter-Glo ${ }^{\oplus}$ Luminescent cell viability assay. Data are represented as the mean \pm SEM for four individual experiments. (C) Apoptosis of PEMs was assessed by FACS, representative images. (D,E) Quantitative analysis (mean \pm SEM) of three experiments individually for early apoptosis (D) and late apoptosis (E). NS indicates P>0.05. GENT, gentiopicroside; PBS, phosphate buffer solution; PEM, peritoneal elucidated macrophage.

reagent (Invitrogen, Carlsbad, CA, USA), and cDNAs were generated with Reverse Transcriptase M-MLV (Takara, cat. \# 2641A), dNTP mix (Thermo Scientific, Lot 00314428), and Random Primer OligodN6 (Sangon Biotech Co., Ltd., Shanghai, China). The relative mRNA expression of IL$1 \beta$, IL-6, iNOS, CCL5, CXCL10 and p65 was measured in duplicate on a BIO-RAD CFX96 machine (Bio-Rad
Laboratories) with SYBR Premix Ex Taq (Takara, cat. \# RR420). All mRNA expression listed above was normalized to the housekeeping gene $\beta$-actin. The qPCR primers are listed in Table 1.

\section{Cell viability assay}

Raw 264.7 cells $\left(1 \times 10^{4}\right.$ per well) were seeded into 96- 
Table 1 Sequences of primers used in the real-time polymerase chain reaction

\begin{tabular}{|c|c|c|c|c|}
\hline Genes & Sequences of primers & $\begin{array}{c}\text { GenBank accession } \\
\text { number }\end{array}$ & $\begin{array}{l}\text { Annealing } \\
\operatorname{Tm}(\mathrm{nn})\end{array}$ & $\begin{array}{l}\text { Product } \\
\text { size (bp) }\end{array}$ \\
\hline$I L-1 \beta$ & F: 5' CTGGTACATCAGCACCTCAC 3', R: 5' AGAAACAGTCCAGCCCATAC 3' & NM_008361.4 & 55 & 124 \\
\hline$T N F-\alpha$ & F: 5' AGTGACAAGCCTGTAGCCC 3', R: 5' GAGGTTGACTTTCTCCTGGTAT 3' & NM_013693.3 & 57 & 252 \\
\hline CCL5 & F: TTTGCCTACСTCTCCСTCG3', R: CGACTGCAAGATTGGAGCACT3' & NM_013653 & 61 & 85 \\
\hline NOS2 & F: 5' GGAGTGACGGCAAACATGACT 3', R: 5' TCGATGCACAACTGGGTGAAC 3' & NM_001313922.1 & 52 & 127 \\
\hline p65 & F: 5' GATTGAAGAGAAGCGCAAAA 3', R: 5' CAGAAGTTGAGTTTCGGGTA 3' & NM_009045.4 & 55 & 131 \\
\hline$\beta$-actin & F: 5' CGTTGACATCCGTAAAGACC 3', R: 5' TAGGAGCCAGAGCAGTAATC 3' & NM_007393.5 & 56 & 110 \\
\hline
\end{tabular}

$I L-1 \beta$, interleukin-1 $\beta$; IL-6, interleukin-6; TNF- $\alpha$, mouse tumor necrosis factor $\alpha$; NOS2, inducible nitric oxide synthase 2; CXCL10, Mus musculus chemokine (C-X-C motif) ligand 10 (Cxcl10); CCL5, chemokine (C-C motif) ligand 5; F, forward primer; R, reverse primer.

well plates containing $200 \mu \mathrm{L}$ of complete DMEM. Cell viability was examined by a CellTiter-Glo ${ }^{\circledR}$ Luminescent Cell Viability Assay (Promega Corporation) following the manufacturer's instructions.

\section{Flow cytometry}

PEMs $\left(0.8 \times 10^{6}\right.$ per well) were seeded into 12 -well plates cultured with $1 \mathrm{~mL}$ of complete DMEM. After 12 hours of incubation with $1,000 \mu \mathrm{g} / \mathrm{mL}$ GENT, the cells were harvested for staining. Briefly, fresh cells were stained with anti-Annexin V-APC antibody (BD, cat. \# 556454) for 40 minutes, and after washing with phosphate buffer solution (PBS), the cells were suspended with $200 \mu \mathrm{L}$ of FACS buffer (PBS + $2 \%$ FBS $+2 \%$ sodium azide) and stained with $0.5 \mu \mathrm{L}$ of propidium iodide (PI, $100 \mu \mathrm{g} / \mathrm{mL}$, Sigma-Aldrich Trading Co., Ltd., Shanghai, China, cat. \# P4170). After $70 \mu \mathrm{m}$ filtration, samples were tested by an Accuri C6 (BD Biosciences, San Jose, CA, USA).

\section{Enzyme linked immunosorbent assay (ELISA) assay}

The blood was obtained from the orbit of mice and added into 1.5-mL Eppendorf tubes after anesthesia (4\% chloral hydrate). After 30 minutes at room temperature, the serum was collected after centrifugation at 4,000 rpm for $20 \mathrm{~min}$. For cell supernatant, BMMs were incubated with GENT for 3 hours followed by stimulation with LPS/IFN- $\gamma$ for another 6 hours. Then, the cell supernatant was collected and centrifuged at $1200 \mathrm{rpm}$ for $10 \mathrm{~min}$ to remove cells. IL- 6 and TNF- $\alpha$ in serum and cell supernatant were quantified by ELISA kits according to the manufacturer's instructions (BD, cat. \# 550950 and 560923).

\section{Histology}

The lungs were harvested at the indicated time points, fixed by $4 \%$ paraformaldehyde for 24 hours at room temperature and embedded in paraffin. Sections ( $5 \mu M$ thick) were cut and stained with hematoxylin and eosin (H\&E). Images were taken by an Olympus BX-81.

\section{Immunofluorescence staining of lung tissue}

Lung tissue sections were stained with primary rat monoclonal antibody against mouse F4/80 (Abcam, cat. \# ab6640) and primary rabbit polyclonal antibody against mouse iNOS (Abcam, cat. \# ab15323) overnight at $4{ }^{\circ} \mathrm{C}$. After washing with PBS, sections were incubated for one hour at room temperature with a corresponding secondary antibody (Abcam, cat. \# ab150167 and ab150077). The sections from the mock group were used as controls. The nuclei were stained by DAPI (sigma, cat. \# D9564). The images were taken by an Olympus BX-81.

\section{Immunofluorescence staining of cells}

PEMs were fixed by $4 \%$ paraformaldehyde for 10 minutes at room temperature, permeabilized by $0.5 \%$ Triton-X, and blocked for 30 minutes at room temperature by $3 \%$ bovine serum albumin (BSA). Cells on coverslips were incubated with anti-NF-kB p65 antibody (Abcam, cat. \# ab16502) overnight and goat anti-rabbit secondary antibody (Abcam, cat. \# ab150077) for 1 hour. The nuclei were dyed with Hoechst 33342 on cell coverslips. Images were also taken by 
an Olympus BX-81. Three hundred cells in different views were counted, and the experiments were replicated 3 times individually.

\section{Western blot assay}

BMMs were stimulated with GENT or PBS for 3 hours followed by treatment with LPS/IFN- $\gamma$ for $0,15,30$ and 60 minutes. At different time points, the cells were lysed by SDS-loading buffer and boiled for $10 \mathrm{~min}$. Lysates were separated by sodium dodecyl sulfate polyacrylamide gel electrophoresis (SDS-PAGE) and transferred thereafter to PVDF membranes. After blocking in Tris buffered saline Tween (TBST) with 5\% BSA for 1 hour at room temperature, the membrane was incubated with primary antibodies, such as using Phospho-IKK $\alpha$ (Ser176)/IKK $\beta$ (Ser177) antibody (cat. \# 2688), Phospho-NF-кB p65 (Ser536) (93H1) Rabbit mAb (cat. \# 3033), ІкB $\alpha$ (44D4) Rabbit mAb (cat. \# 4812), Phospho-SAPK/JNK (Thr183/ Tyr185) (81E11) Rabbit mAb (cat. \# 4668), Phospho-p44/42 MAPK (Erk1/2) (Thr202/Tyr204) (D13.14.4E) XP ${ }^{\circledR}$ Rabbit mAb (cat. \# 4370) or Phospho-p38 MAPK (Thr180/Tyr182) (D3F9) $\mathrm{XP}^{\circledR}$ Rabbit mAb (cat. \# 4511) overnight at $4{ }^{\circ} \mathrm{C}$ and corresponding horseradish peroxidase-labeled secondary antibodies (cat. \# 7074), while GAPDH (D16H11) XP ${ }^{\circledR}$ Rabbit mAb (cat. \#5174) was coupled to horseradish peroxidase itself. All antibodies came from Cell Signaling Technology. Detection was performed with ECL substrate (Thermo Scientific, cat. \# 32109). Digital images were taken by a MiniChemi from SAGECREATION, Beijing, China.

\section{Statistical analysis}

Statistical analysis was conducted by using GraphPad Prism (Version 6.0). Data represent the mean \pm SEM. A log-rank (Mantel-Cox) test was applied to calculate mouse survival rates; statistical significance was determined by an unpaired or paired two-tailed Student's $t$-test (or nonparametric test) with $95 \%$ confidence intervals or a one-way ANOVA (or nonparametric). A $\mathrm{P}$ value $<0.05$ was considered to be statistically significant $\left({ }^{*} \mathrm{P}<0.05\right)$.

\section{Results}

\section{GENT did not have any effect on the viability and apoptosis of RAW264.7 cells}

To avoid the toxic effects of GENT, we first investigated the effect of GENT on the survival of RAW264.7 cells.
Cells were treated with or without $1,000 \mu \mathrm{g} / \mathrm{mL}$ GENT for 24, 48 and $72 \mathrm{~h}$. Cell viability was analyzed by the CellTiter-Glo ${ }^{\circledR}$ Luminescent Cell Viability Assay, and the apoptosis ratio was assessed by flow cytometry with PI/ Annexin V. The results revealed that cell viability did not differ significantly at any time point when the macrophages were treated with $1,000 \mu \mathrm{g} / \mathrm{mL}$ GENT (Figure 1B). Cell apoptosis did not show any significant difference under GENT treatment for $24 \mathrm{~h}$ (Figure 1C,D,E), suggesting that GENT does not have any toxic effect on the viability and apoptosis of RAW264.7 cells in vitro.

\section{GENT reduced the production of pro-inflammatory cytokines, chemokines and mediators in LPS-induced macrophages}

It is well-known that IL-1 $\beta$, TNF- $\alpha$, IL-6 and CXCL10 are critical pro-inflammatory cytokines or chemokines produced in response to LPS, while iNOS and CCL5 are an important inflammatory mediator and a chemokine, respectively (31-34). BMMs were pretreated by GENT (500 or $1,000 \mu \mathrm{g} / \mathrm{mL}$ ) for 3 hours, and then LPS $(1 \mu \mathrm{g} / \mathrm{mL})$ and IFN- $\gamma(100 \mathrm{ng} / \mathrm{mL})$ were added for 6 hours. The results showed that GENT decreased the mRNA levels of IL- $1 \beta$, TNF- $\alpha$, IL-6, CXCL10, iNOS and CCL5 in a concentration-dependent manner induced by LPS/IFN- $\gamma$ (Figure $2 A, B, C, D, E, F$ ). Moreover, GENT decreased the protein levels of IL- 6 and TNF- $\alpha$ in the supernatant of LPS-activated macrophages in a dose-dependent manner, determined by testing the cell culture supernatant (Figure 2G,H). In addition, Raw264.7 cells were pretreated by GENT at $40 \mu \mathrm{g} / \mathrm{mL}$ or $80 \mu \mathrm{g} / \mathrm{mL}$ for 3 hours, then LPS $(100 \mathrm{ng} / \mathrm{mL})$ and IFN- $\gamma(100 \mathrm{ng} / \mathrm{mL})$ were added for 6 hours, and we found that GENT decreased IL-1 $\beta$, IL- 6 and TNF- $\alpha$ mRNA expression in a dose-dependent manner (Figure 2I,, , K). All of these studies demonstrated that GENT inhibited the expression of proinflammatory cytokines, chemokines and mediators in LPS/ IFN- $\gamma$-induced macrophages.

\section{GENT attenuated the phosphorylation of IKK $\alpha / \beta$ and $p 65$ without any effect on MAPK signaling}

Both NF-kB and MAPK (JNK 1/2, p38 MAPK and ERK $1 / 2$ ) have been implicated as key factors in regulating the production of pro-inflammatory mediators and cytokines $(29,35)$. Thus, we examined whether GENT regulates the activation of MAPKs or NF- $\kappa B$ signaling by LPS/IFN$\gamma$-activated macrophages. We found that GENT strongly 
A

IL-1 $1 \beta$

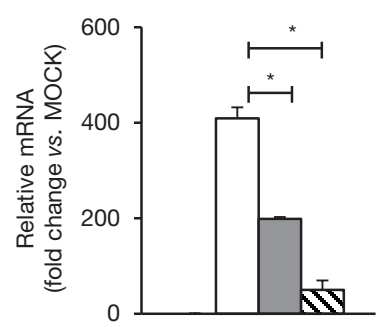

iNOS

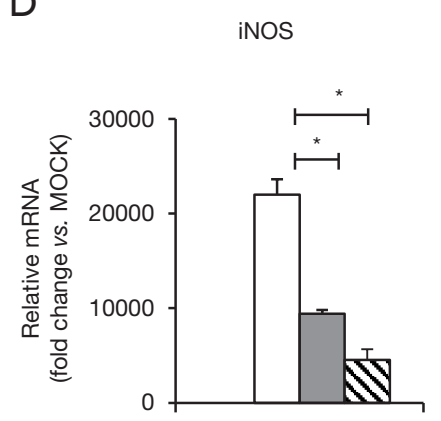

G

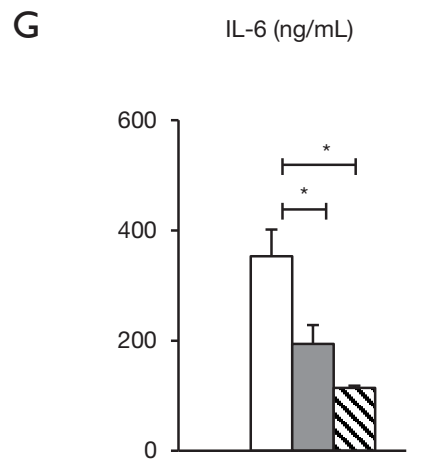

B

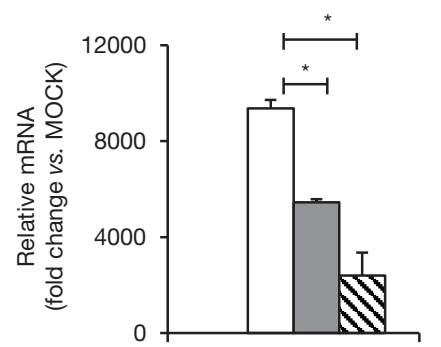

$E$

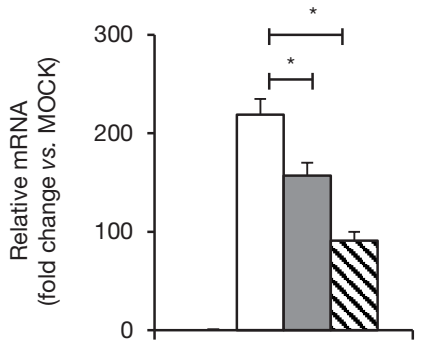

$\mathrm{H}$

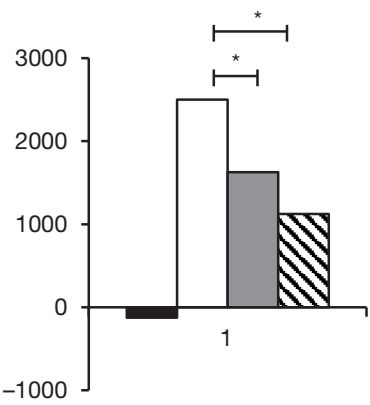

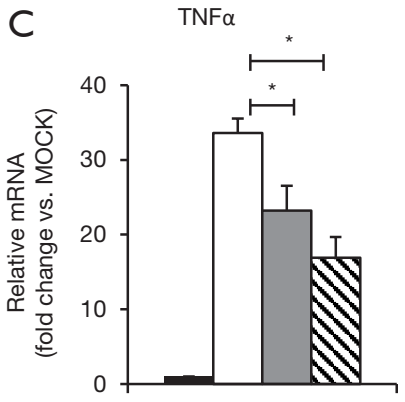

$\mathrm{F}$

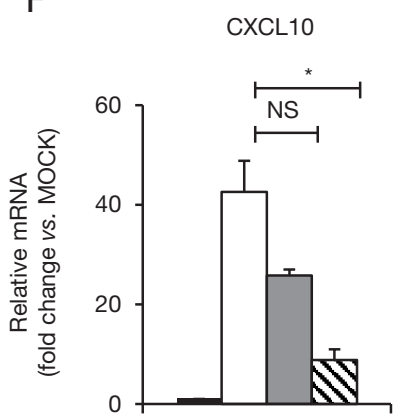

I

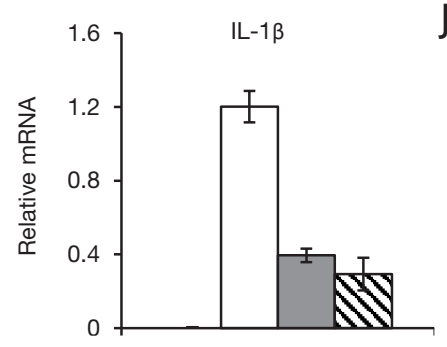

J

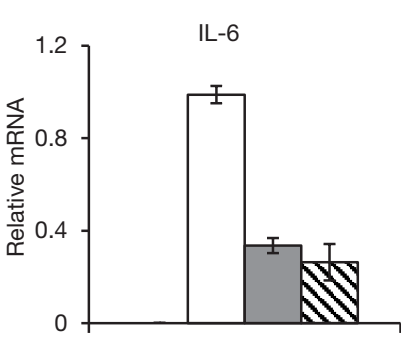

$\mathrm{K}$

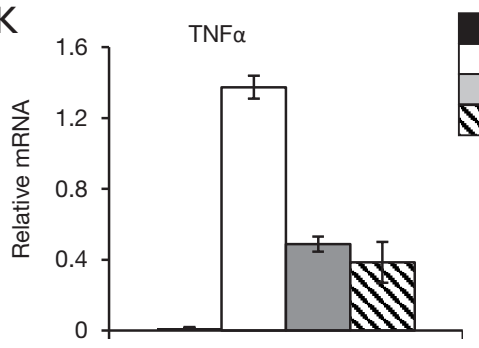

Mock

LPS/IFN $\gamma$

LPS/IFN $\gamma+$ GENT20 $\mu \mathrm{g} / \mathrm{mL}$ S LPS/IFN $\gamma+$ GENT40 $\mu \mathrm{g} / \mathrm{mL}$

Figure 2 GENT ameliorated the inflammatory cytokine production of BMMs stimulated by LPS/IFN- $\gamma$. (A,B,C,D,E,F,G,H) BMMs were pretreated with GENT (500 or $1,000 \mu \mathrm{g} / \mathrm{mL}$ ) or the same volume of PBS for $3 \mathrm{~h}$, and then LPS $(1 \mu \mathrm{g} / \mathrm{mL}) / \mathrm{IFN}-\gamma(100 \mathrm{ng} / \mathrm{mL}) \mathrm{was}$ added; 6 hours later, the RNA and supernatants of BMMs were isolated. (A,B,C,D,E,F) The mRNA levels of IL-1 $\beta$, IL-6, TNF- $\alpha$, iNOS, CCL5 and CXCL10 of BMMs were determined by qPCR. Error bars represent the mean \pm SEM, representative of at least three experiments. (G,H) The protein levels of IL- 6 and TNF- $\alpha$ in the supernatant of BMM were analyzed by ELISA assay. (I,J,K) RAW264.7 cells were pretreated with GENT (40 or $1000 \mu \mathrm{g} / \mathrm{mL}$ ) or the same volume of PBS for $3 \mathrm{~h}$, and then LPS $(1 \mu \mathrm{g} / \mathrm{mL}) / \mathrm{IFN}-\gamma(100 \mathrm{ng} / \mathrm{mL})$ was added; $6 \mathrm{hours}$ later, the RNA and supernatants of RAW264.7 were isolated. Data are represented as the mean \pm SEM for three individual experiments. * indicates $\mathrm{P}<0.05$. GENT, gentiopicroside; BMM, bone marrow-derived macrophage; LPS, lipopolysaccharide; IFN, interferon; PBS, phosphate buffer solution; IL, interleukin; TNF, tumor necrosis factor; ELISA, enzyme linked immunosorbent assay. 
decreased the phosphorylation of IKK $\alpha / \beta$ and p 65 and $\mathrm{I} \kappa \mathrm{B} \alpha$ degradation in $\mathrm{BMMs}$ in a corresponding manner, as expected. While we did not find any obvious changes in the phosphorylation of JNK 1/2, p38 MAPK and ERK 1/2, even these factors were activated by LPS/IFN- $\gamma$ (Figure 3).

\section{GENT inbibited LPS/IFN- $\gamma$-induced p65 transportation to the nucleus}

We also investigated whether GENT could interfere with the translocation of the p65 subunit of NF- $\mathrm{KB}$ from the cytosol to the nucleus in PEMs. We found that in LPS/ IFN- $\gamma$-treated cells, most intracellular p65 translocated from the cytoplasm to the nucleus, as shown by strong NF$\kappa \mathrm{B}$ p65 staining in the nucleus (Figure $4 A$ ). The level of p65 in the nucleus was significantly reduced by pretreatment with GENT $(1,000 \mu \mathrm{g} / \mathrm{mL})$ in an immunofluorescence assay at 15,30 and 60 minutes (min) (Figure 4B). All immunofluorescent staining was performed simultaneously.

\section{p65 siRNA or IKK/IКB inbibitor botb abolished the inbibitory effect of GENT on inflammatory cytokine expression}

To further identify how GENT exerts an inhibitory effect on inflammatory cytokine expression through the NF- $\kappa \mathrm{B}$ signaling pathway, we applied two p65 siRNAs

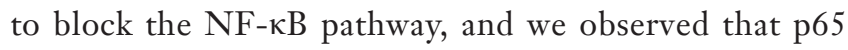
knockdown could significantly reduce LPS/IFN- $\gamma$-induced inflammatory cytokine expression, including IL-1 $\beta$, IL-6 and iNOS, as expected, while p65 siRNAs diminished the inhibitory effect of GENT on LPS/IFN- $\gamma$-induced inflammatory cytokine expression (Figure $5 A, B, C, D$ ). Next, we pretreated macrophages with an inhibitor of IKK/ІкB (BAY117082, Sigma, CAS: 19542-67-7) following LPS/ IFN- $\gamma$ or LPS/IFN- $\gamma+$ GENT. We also observed that blocking IKK/IкB could strongly decrease the expression of cytokines, while GENT lost its inhibitory effect when pretreated with BAY117082. This finding indicated that

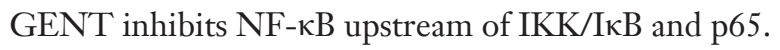

\section{GENT protected mice against from LPS-induced shock, acute lung injury, and inflammatory cytokine release}

To elucidate the inhibitory effect of GENT on LPSinduced septic shock, mice were treated with GENT 30 minutes before intraperitoneal injection of LPS following injection of GENT, which was repeated 8 times

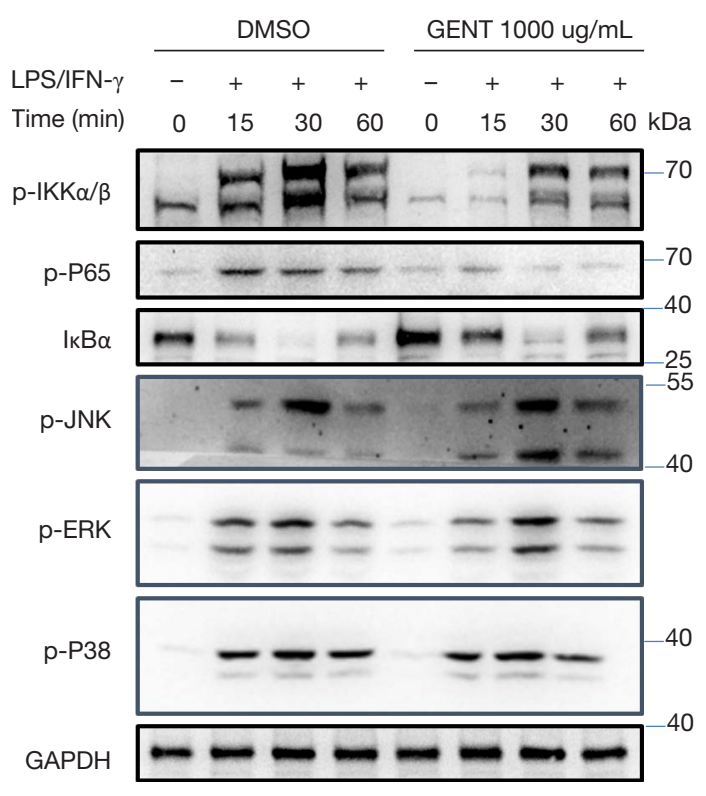

Figure 3 GENT ameliorated the phosphorylation of IKK $\alpha / \beta$ and P65 without any obvious effect on MAPK signaling under LPS/ IFN- $\gamma$ stimulation. BMMs were pre-stimulated with GENT or DMSO for 3 hours, then treated with LPS $(1 \mu \mathrm{g} / \mathrm{mL}) / \mathrm{IFN}-\gamma$ $(100 \mathrm{ng} / \mathrm{mL})$. The phosphorylation of IKK $\alpha / \beta, \mathrm{P} 65$, JNK, ERK, and P38 and the protein levels of I $\mathrm{KB} \alpha$ and GAPDH were determined by Western blotting at 15, 30 and 60 minutes after LPS/IFN- $\gamma$ stimulation. The experiment was repeated 3 times. The grouping of blots is due to cropping from the same batch of samples, although in different parts of different gels. GENT, gentiopicroside; LPS, lipopolysaccharide; IFN, interferon; BMM, bone marrow-derived macrophage.

(Figure 6A). The survival rates of animals in the LPS and GENT groups were recorded and analyzed. All mice died 16 to 48 hours after receiving the lethal dose of LPS (Figure 6B). However, the fatality of mice was significantly abated when they received GENT (50 mg/kg, i.p.) before and after LPS treatment (Figure 6B), indicating GENT is a helpful candidate for treating septic shock. Lung tissues were harvested at 2 and 4 hours after LPS injection and subjected to H\&E staining for histological analysis. Normal pulmonary histology was shown in the mock group without LPS and GENT treatment. LPS treatment for 2 and 4 hours induced the infiltration of inflammatory cells in the lung interstitium and alveolar spaces and the thickening and congestion of the alveolar wall, while pretreatment with GENT notably alleviated these pathological changes induced by LPS (Figure 6C). In addition, the mRNA levels of IL-1 $1 \beta$, 
A
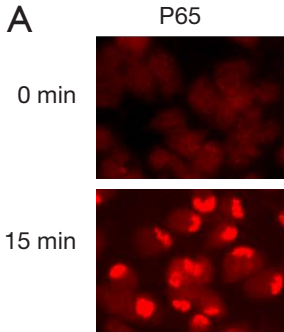

$30 \mathrm{~min}$

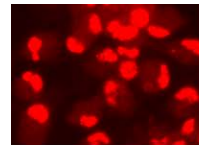

$60 \mathrm{~min}$

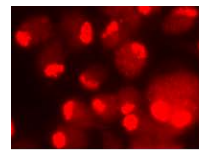

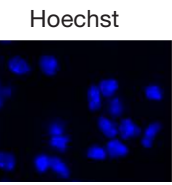
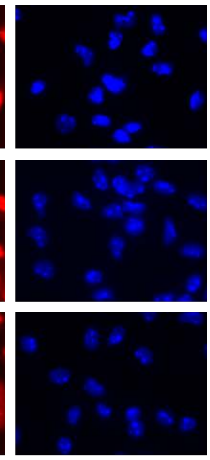

DMSO +LPS/IFN- $\gamma$
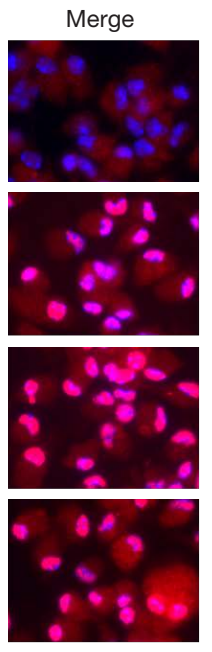
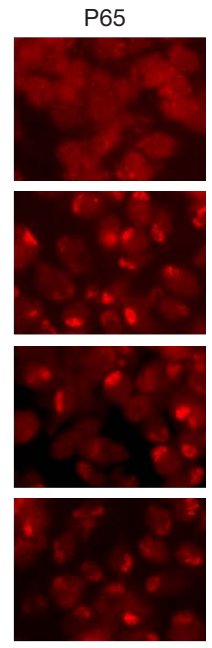

GENT $1000 \mu \mathrm{g} / \mathrm{mL}$
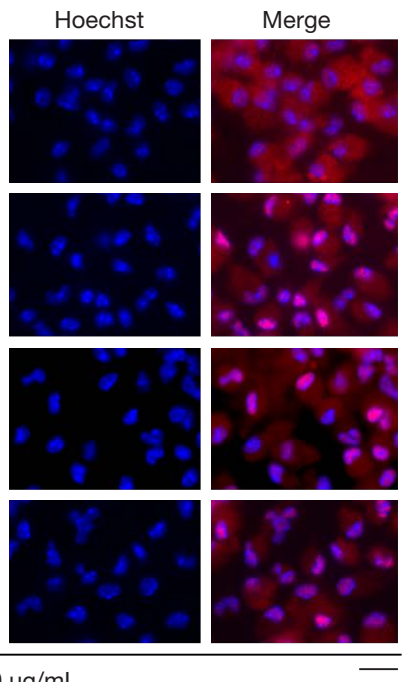

$20 \mu \mathrm{m}$

B

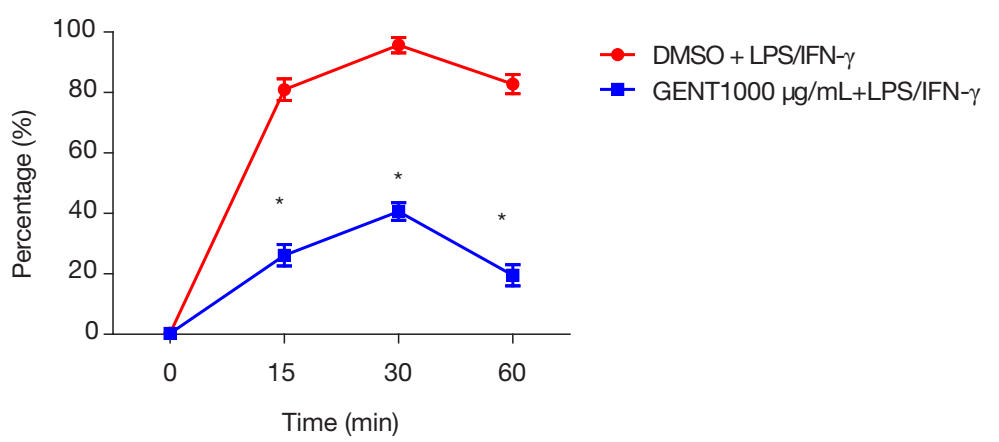

Figure 4 GENT inhibited LPS/IFN- $\gamma$-induced P65 transportation to the nucleus. PEMs were stimulated with GENT (1,000 $\mu$ g/mL) or DMSO for 3 hours followed by LPS/IFN- $\gamma$ treatment for another 0, 15, 30 and 60 minutes. The transportation of P65 was determined for immunofluorescent staining by using an anti-p65 antibody (red). Hoechst was used to counterstain nuclei (blue) prior to fluorescent microscopy. (A) Representative images illustrated colocalization of P65 and the nuclei (100x). (B) The percentages of P65 in the nucleus were quantified. More than 300 cells from each sample were measured. The experiment was duplicated. * indicates P<0.05. GENT, gentiopicroside; LPS, lipopolysaccharide; IFN, interferon; PEM, peritoneal elucidated macrophage.

TNF $\alpha$ and IL-6 of lung tissue were significantly upregulated after LPS administration at each time point, while GENT clearly ameliorated IL-1 $\beta$ and TNF $\alpha$ expression at 4 hours and IL-6 expression at 2 hours (Figure $6 D, E, F$ ). On the other hand, we tested the protein levels of IL-1 $\beta$, TNF $\alpha$ and IL-6 in the serum of mice and observed that LPS also stimulated IL- $1 \beta, T N F \alpha$ and IL- 6 production in the peripheral blood at two time points. Pretreatment with GENT significantly reduced IL-1 $\beta$ levels at 2 hours and IL-6 level at 4 hours without any effect on TNF $\alpha$ levels at both time points (Figure $6 G, H, I)$. These data demonstrated the protective effects of GENT against LPS-induced sepsis in mice.

\section{GENT attenuated M1 type macrophage infiltration in mouse lung tissues}

To further confirm the inhibitory effect of GENT on the inflammatory response expression of macrophages in vivo, we performed double immunofluorescence (IF) staining of lung tissue by using anti-F4/80 and iNOS primary antibodies. F4/80 is a specific antigen for macrophages (36-38). iNOS is an important pro-inflammatory mediator expressed by macrophages under LPS induction (39-41). Thus, positive staining of both F4/80 and iNOS indicates macrophages are activated and are able to produce high levels of cytokines. In our study, LPS treatment markedly 
A

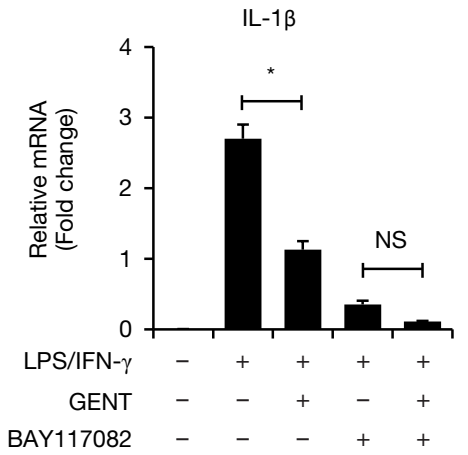

IL-1 $\beta$

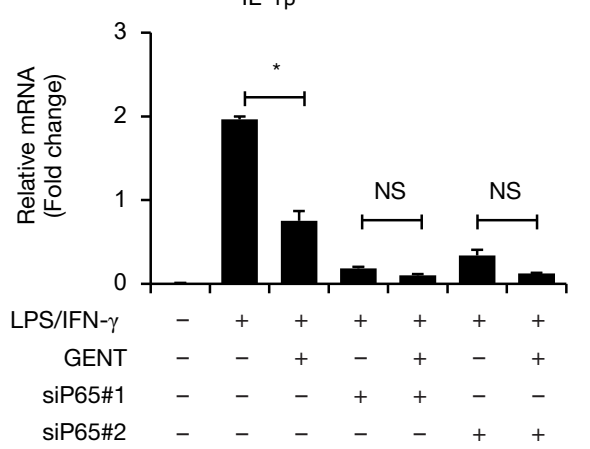

$\mathrm{F}$

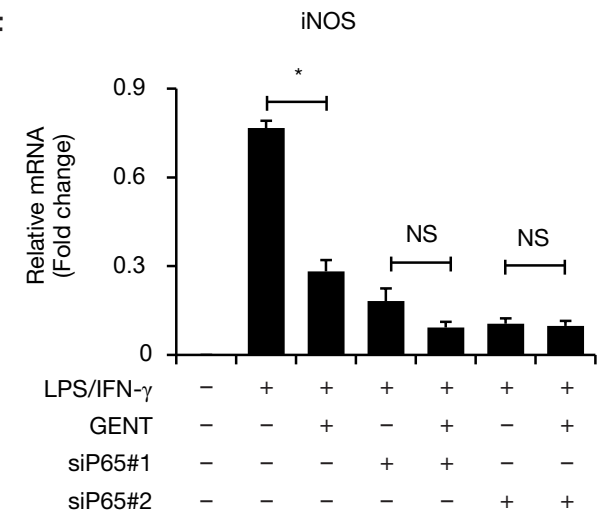

B

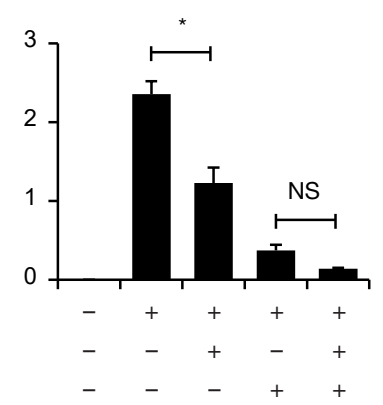

E

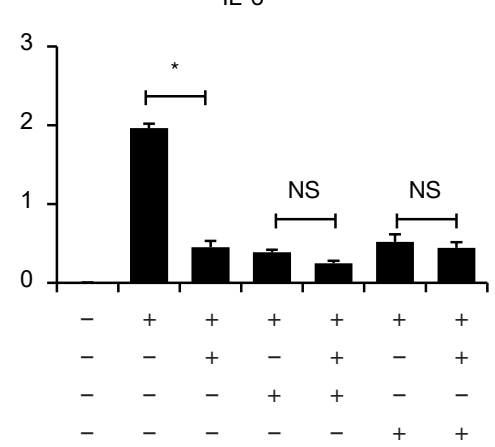

G

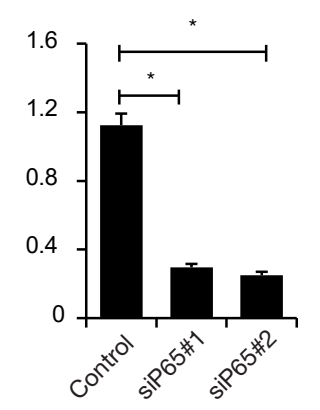

Figure $5 \mathrm{NF \kappa B}$ inhibitor and siP65 abolished the inhibitory effect of GENT on inflammatory cytokine production by PEMs and BMMs induced by LPS/IFN- $\gamma$. (A,B,C) BMMs were treated with $5 \mu \mathrm{M} \mathrm{NF \kappa B}$ inhibitor (BAY117082) for $1 \mathrm{~h}$, followed by GENT (1,000 ng/mL) for $3 \mathrm{~h}$ and LPS/IFN- $\gamma$ for another 6 hours. The mRNA levels of IL-1 $\beta$, IL-6 and iNOS of BMM were determined by qPCR. (D,E,F) PEMs were transfected with siP65\#1 and siP65\#2 for 48 h, followed by GENT (1,000 ng/mL) for $3 \mathrm{~h}$ and LPS/IFN- $\gamma$ for another 6 hours. The mRNA levels of IL-1 $\beta$, IL-6 and iNOS of PEM were determined by qPCR. (G) PEMs were transfected with siP65\#1 and siP65\#2 for 48 h. The inhibitory efficiency of two siRNAs for P65, siP65\#1 and siP65\#2, in PEMs was determined by qPCR. Error bars represent the mean \pm SEM, and all experiments were repeated at least three times. * indicates $\mathrm{P}<0.05$, NS indicates $\mathrm{P}>0.05$. GENT, gentiopicroside; LPS, lipopolysaccharide; IFN, interferon; PEM, peritoneal elucidated macrophage; BMM, bone marrow-derived macrophage.

increased iNOS-positive macrophage infiltration of lung tissue, while GENT distinctly decreased F4/80 and iNOS single-positive cells and double-positive cells at each time point (Figure 7), suggesting that GENT alleviated LPSinduced M1 macrophage infiltration in the lung.

\section{Discussion}

Septic shock is a dangerous manifestation of the systemic inflammatory response to microbial infection, resulting in multiple organ failure. LPS, an outer membrane 
A

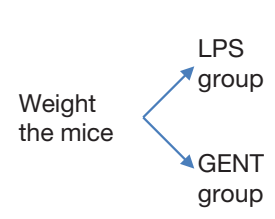

Inject physiological saline, the volume is the same as the GENT group

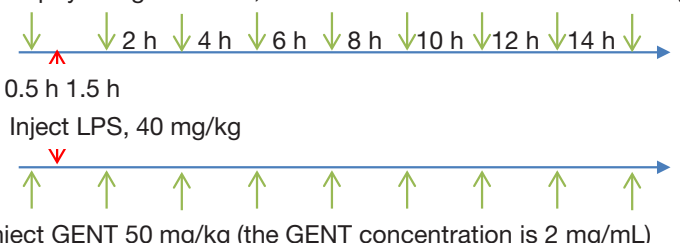

Inject GENT $50 \mathrm{mg} / \mathrm{kg}$ (the GENT concentration is $2 \mathrm{mg} / \mathrm{mL}$ )

B

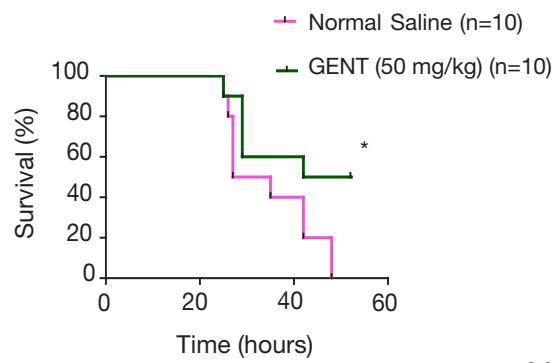

$\mathrm{D}$

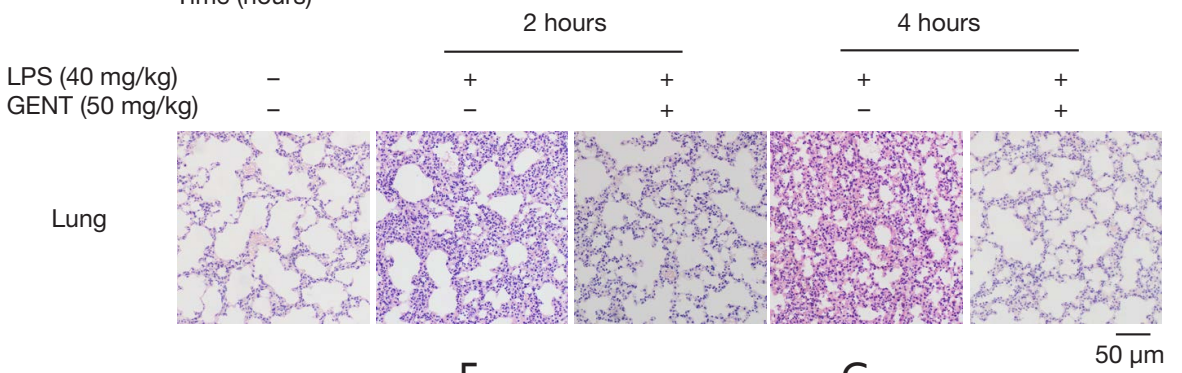

$E$
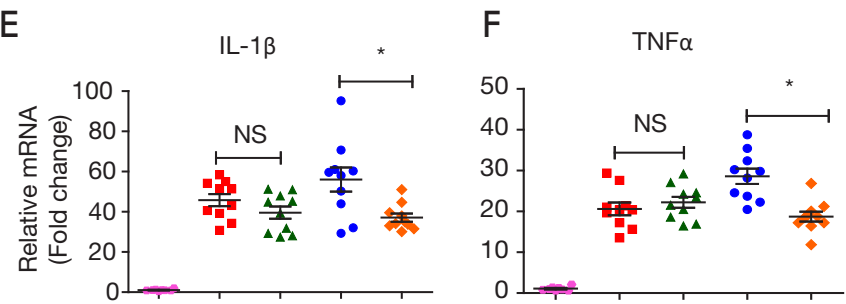

G

IL-6

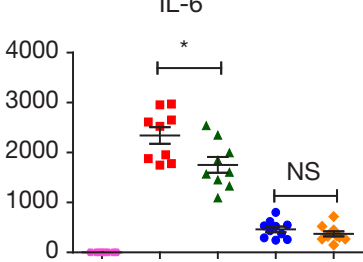

$\mathrm{H}$
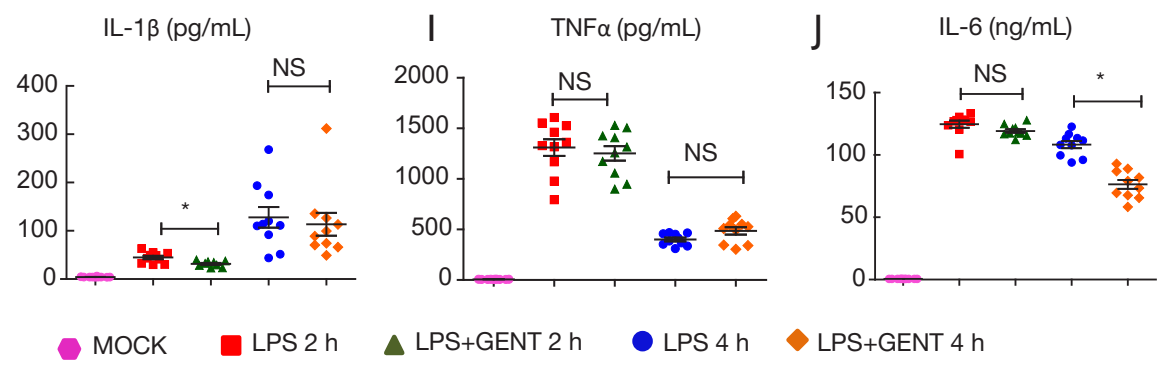

LPS+GENT $4 \mathrm{~h}$

Figure 6 GENT improved the survival rate and protected against acute lung injury and inflammatory cytokine release in endotoxemic mice. (A) The experimental procedure was conducted to determine the survival rate. Briefly, the C57BL/6 mice were pre-treated with GENT or saline for $30 \mathrm{~min}$, followed by LPS i.p. injection. Then, $1.5 \mathrm{~h}$ after LPS injection, GENT or saline was injected repeatedly 7 times, with one injection every 2 hours. (B) The survival rates of C57BL/6 mice that were i.p. injected with LPS plus GENT (green line) or saline (pink line) ( $n=10$ /group). The experiments were repeated in triplicate. (C) The experimental procedure was conducted to determine IL-1 $\beta$, IL-6 and TNF $\alpha$ in the serum and mRNA. The mice were pre-treated with GENT or physiological saline for 30 min, following LPS i.p. injection for 2 and 4 hours. (D) Representative images of H\&E stained lung paraffin sections. (E,F,G) IL-1 $\beta$, IL-6, and TNF- $\alpha$ mRNA expression of lung tissue were determined by qPCR. (H,I,J) The cytokine levels of IL-1 $\beta$, IL- 6 and TNF- $\alpha$ in the serum were measured by using an ELISA kit. In E-J, each dot represents a single mouse. * indicates $\mathrm{P}<0.05$, NS indicates $\mathrm{P}>0.05$. GENT, gentiopicroside; LPS, lipopolysaccharide; IL, interleukin; TNF, tumor necrosis factor. 


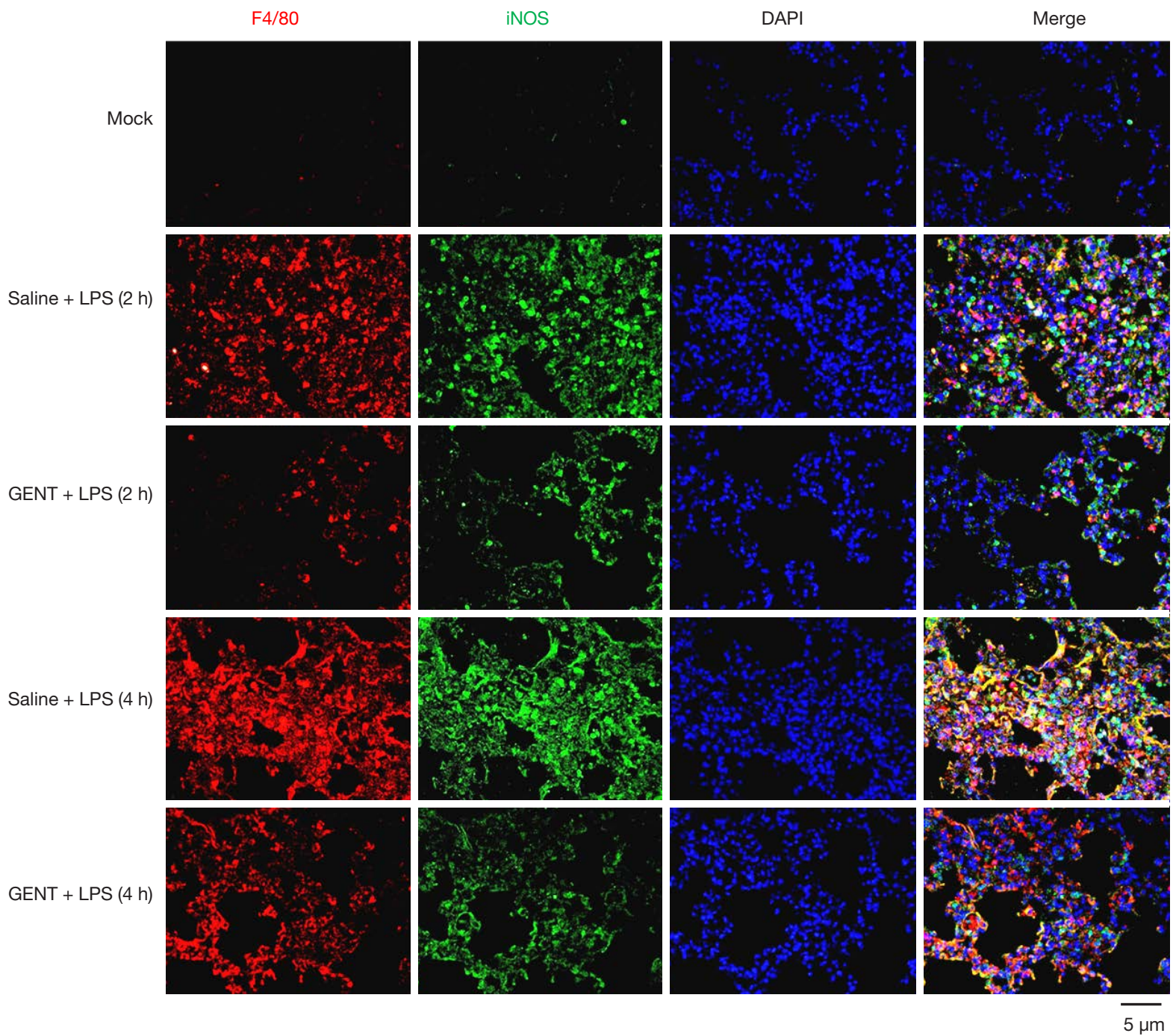

Figure 7 Large numbers of iNOS-expressing F4/80+ macrophages in lung tissue induced by LPS was reduced by GENT pretreatment. Representative immunofluorescence staining images by using anti-iNOS (green) and anti-F4/80 (red) antibodies in paraffin sections of lung tissue from mice pre-treated with saline and GENT for $30 \mathrm{~min}$ following LPS injection at 2 and 4 hours (n=10/group). GENT, gentiopicroside; LPS, lipopolysaccharide.

component of gram-negative bacteria, is a strong activator that stimulates monocytes/macrophages to release multifarious inflammatory cytokines. Importantly, LPSinduced septic shock in an animal model is similar to the clinical manifestation of patients. Studies investigating the effect of drugs on LPS-induced inflammatory cytokines and activated signaling pathways in macrophages may have critical implications in exploring and evaluating treatment for sepsis. Therefore, we initially sought to identify the anti-inflammatory effect of GENT on LPS/ IFN $\gamma$-induced macrophages. In the current study, GENT significantly inhibited the expression of inflammatory cytokines, chemokines and mediators of LPS/IFN $\gamma$ induced macrophages. Consistent with the results of our study, several previous studies suggested that GENT has an anti-inflammatory effect. For example, GENT prevented the IL-1 $\beta$-induced inflammatory response in rat articular chondrocytes (27), attenuated acute pancreatitis in rats (30), reduced dextran sulfate sodium (DSS)-induced colitis in mice (30), and protected against both $\mathrm{CCl} 4$-induced and LPS/bacillus Calmette-Guerin (BCG)-induced hepatitis (21). However, Yamada et al. (23) indicated that 


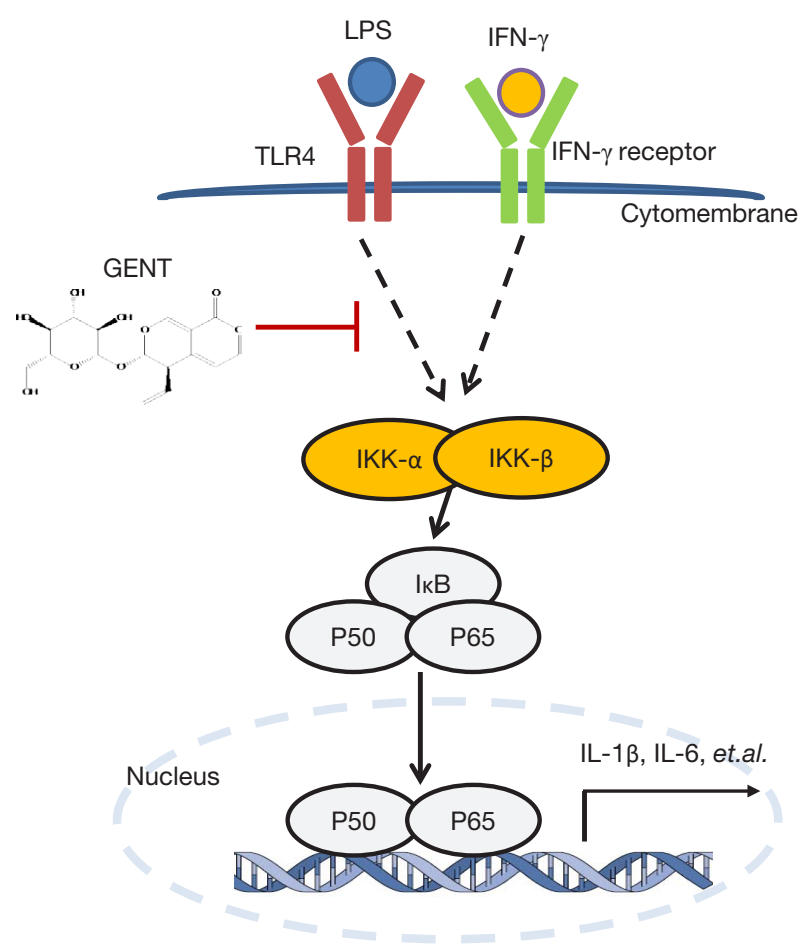

Figure 8 Diagram illustrating the inhibitory effect of GENT. GENT, gentiopicroside.

gentiolactone in an extract of gentian root could inhibit the production of TNF- $\alpha$ induced by LPS, and the other two extracts, gentiopicroside and swertiamarin, did not have such an effect, which was inconsistent with the results of our study, which showed that GENT could reduce the inflammatory reaction induced by LPS and IFN- $\gamma$ in primary macrophages (BMMs and PEMs). This difference may be observed because we did not use the same stimulus; we used LPS and IFN- $\gamma$, while the previous study only used LPS. Meanwhile, the treatment procedure was also different: we treated cells with GENT $(1,000 \mu \mathrm{g} / \mathrm{mL})$ 30 minutes before LPS/IFN- $\gamma$, while Yamada et al. cultured cells with LPS $(100 \mathrm{ng} / \mathrm{mL})$ and 60,300 or $1,500 \mu \mathrm{M}$ GENT. In addition, different cell types may have diverse responses, and the previous study employed Raw264.7 cells, while we used primary macrophages to test the efficiency of GENT.

Both MAPK and NF- $\kappa$ B signaling are important downstream activities of LPS-TLR4 signaling in the pro-inflammatory cytokine production of activated macrophages. Pretreatment with GENT suppressed LPSinduced I $\kappa$ B protein degradation, the phosphorylation of p65 and p65 nuclear import, which suggested that
$\mathrm{NF}-\kappa \mathrm{B}$ nuclear localization signals are maintained in an inactive state when treated with GENT, and NF- $\kappa \mathrm{B}$ inactivation inhibits downstream transcription and the expression of pro-inflammatory cytokines, such as TNF- $\alpha$, IL-1 $\beta$ and IL-6 (31-34). In order to determine whether GENT affects the LPS-induced inflammatory response through NF- $\kappa \mathrm{B}$ signaling, we adopted an NF- $\mathrm{KB}$ signaling inhibitor and two p65 siRNAs to block and abolish NF$\mathrm{\kappa B}$ signaling transcription and found that GENT lost its anti-inflammatory effect. This result indicated that GENT

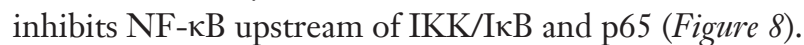

As an in vivo study showed that GENT inhibited the release of inflammatory mediators and NF- $\mathrm{KB}$ p 65 protein expression in acute pancreatitis (30), we could conclude that GENT suppressed inflammatory cytokine expression by blocking the NF- $\kappa \mathrm{B}$ signaling pathway. In addition, GENT was reported to inhibit IL-1 $\beta$-induced phosphorylation of p38, ERK and JNK in rat chondrocytes (27) and LPSinduced hepatocytes (22). However, in the present study, GENT did not have any effect on the LPS/IFN- $\gamma$ induced phosphorylation of MAPK signaling factors in macrophages. This result may be observed because different cell types have distinct signaling responses to GENT.

To the best of our knowledge, GENT was first found to inhibit LPS-induced sepsis and LPS-stimulated production of pro-inflammatory cytokines of macrophages through NF- $\kappa B$ signaling in our study. In addition, GENT reduced the infiltration and inflammatory response of macrophages in the lung. Thus, GENT protects mice against septic death induced by LPS, leading to significant prolongation of survival, possibly because GENT pre-treatment significantly suppresses the serum and pulmonary levels of proinflammatory cytokines, such as IL-1 $\beta$, IL- 6 and TNF- $\alpha$. Our study demonstrated that GENT might protect against LPS-induced sepsis by suppressing pro-inflammatory cytokine production by activated macrophages.

The limitation of GENT is its clearance rate in vivo, which is approximately 3 hours, leading to the necessity for frequent injections to maintain the blood concentration. One approach to reduce injection frequency is to generate targeted agents that can be delivered to injured organs locally, resulting in enhanced local concentrations and slow release, these agents may include nanoparticle-encapsulated drugs, which are currently under research in our laboratory.

In summary, for the first time, we demonstrated that GENT could protect against the endotoxin shock induced by LPS in vivo and inhibit the inflammatory cytokine production in primary macrophages stimulated by LPS/ 
IFN- $\gamma$ through the NF- $\mathrm{KB}$ signaling pathway.

\section{Acknowledgments}

Funding: This work was supported by research grants from the National Natural Science Foundation of China (81822050 and 81673990 to Q Liang, 81730107 to Y Wang, 81330085 to Q Shi), Leading medical talents in Shanghai (2019LJ02 to Q Liang), Dawn plan of Shanghai Municipal Education Commission (19SG39 to Q Liang), the Shanghai TCM Medical Center of Chronic Disease (2017ZZ01010 to Y Wang), the Program for the Innovative Research Team of the Ministry of Science and Technology of China (2015RA4002 to Y Wang), the "Innovation Team" Development Projects (IRT1270 to Y Wang), and the Research Project of Shanghai Science and Technology Commission (17401971100 to Q Liang), Three year action plan of Shanghai to further speed up the development of traditional Chinese Medicine [ZY(2018-2020)-CCCX-3003 to Y Wang].

\section{Footnote}

Conflicts of Interest: The authors have no conflicts of interest to declare.

Ethical Statement: The authors are accountable for all aspects of the work in ensuring that questions related to the accuracy or integrity of any part of the work are appropriately investigated and resolved. All animal protocols were approved by Longhua Hospital, Shanghai, China.

\section{References}

1. Fleischmann C, Scherag A, Adhikari NK, et al. Assessment of global incidence and mortality of hospital-treated sepsis. Current estimates and limitations. Am J Respir Crit Care Med 2016;193:259-72.

2. Walkey AJ, Lagu T, Lindenauer PK. Trends in sepsis and infection sources in the United States. A population-based study. Ann Am Thorac Soc 2015;12:216-20.

3. Cohen J, Vincent J-L, Adhikari NK, et al. Sepsis: a roadmap for future research. Lancet Infect Dis 2015;15:581-614.

4. Seymour CW, Rea TD, Kahn JM, et al. Severe sepsis in pre-hospital emergency care: analysis of incidence, care, and outcome. Am J Respir Crit Care Med 2012;186:1264-71.

5. Zhang Y, Lu Y, Ma L, et al. Activation of vascular endothelial growth factor receptor-3 in macrophages restrains TLR4-NF- $\mathrm{kB}$ signaling and protects against endotoxin shock. Immunity 2014;40:501-14.

6. Dellinger RP, Levy MM, Rhodes A, et al. Surviving Sepsis Campaign: international guidelines for management of severe sepsis and septic shock, 2012. Intensive Care Med 2013;39:165-228.

7. Biswas SK, Lopez-Collazo E. Endotoxin tolerance: new mechanisms, molecules and clinical significance. Trends Immunol 2009;30:475-87.

8. Foster SL, Medzhitov R. Gene-specific control of the TLR-induced inflammatory response. Clin Immunol 2009;130:7-15.

9. Martinez FO, Gordon S. The M1 and M2 paradigm of macrophage activation: time for reassessment. F1000prime Rep 2014;6:13.

10. Udalova IA, Mantovani A, Feldmann M. Macrophage heterogeneity in the context of rheumatic diseases. Nat Rev Rheumatol 2016;12:472-85.

11. Benoit M, Desnues B, Mege JL. Macrophage polarization in bacterial infections. J Immunol 2008;181:3733-9.

12. Bozza FA, Salluh JI, Japiassu AM, et al. Cytokine profiles as markers of disease severity in sepsis: a multiplex analysis. Crit Care 2007;11:R49.

13. López-Bojórquez LN, Dehesa AZ, Reyes-Terán G. Molecular mechanisms involved in the pathogenesis of septic shock. Arch Med Res 2004;35:465-79.

14. Hayden MS, Ghosh S. Regulation of NF-kappaB by TNF family cytokines. Semin Immunol 2014;26:253-66.

15. Hoesel B, Schmid JA. The complexity of NF-kappaB signaling in inflammation and cancer. Mol Cancer 2013;12:86.

16. Vallabhapurapu S, Karin M. Regulation and function of $\mathrm{NF}-\kappa \mathrm{B}$ transcription factors in the immune system. Annu Rev Immunol 2009;27:693-733.

17. Luo MC, Zhou SY, Feng DY, et al. Runt-related Transcription Factor 1 (RUNX1) Binds to p50 in Macrophages and Enhances TLR4-triggered Inflammation and Septic Shock. J Biol Chem 2016;291:22011-20.

18. Gupta SC, Sundaram C, Reuter S, et al. Inhibiting NFkappaB activation by small molecules as a therapeutic strategy. Biochim Biophys Acta 2010;1799:775-87.

19. Hase K, Li J, Basnet P, et al. Hepatoprotective principles of Swertia japonica Makino on D-galactosamine/ lipopolysaccharide-induced liver injury in mice. Chem Pharm Bull (Tokyo) 1997;45:1823-7.

20. He YM, Zhu S, Ge YW, et al. The anti-inflammatory secoiridoid glycosides from gentianae scabrae radix: the root and rhizome of Gentiana scabra. J Nat Med 2015;69:303-12. 
21. Kondo Y, Takano F, Hojo H. Suppression of chemically and immunologically induced hepatic injuries by gentiopicroside in mice. Planta Med 1994;60:414-6.

22. Lian LH, Wu YL, Wan Y, et al. Anti-apoptotic activity of gentiopicroside in D-galactosamine/lipopolysaccharideinduced murine fulminant hepatic failure. Chem Biol Interact 2010;188:127-33.

23. Yamada H, Kikuchi S, Inui T, et al. Gentiolactone, a secoiridoid dilactone from Gentiana triflora, inhibits TNFalpha, iNOS and Cox-2 mRNA expression and blocks NFkappaB promoter activity in murine macrophages. PLoS One 2014;9:e113834.

24. Jia N, Li Y, Wu Y, et al. Comparison of the antiinflammatory and analgesic effects of Gentiana macrophylla Pall. and Gentiana straminea Maxim., and identification of their active constituents. J Ethnopharmacol 2012;144:638-45.

25. Sheu MJ, Chiu CC, Yang DJ, et al. The Root Extract of Gentiana macrophylla Pall. Alleviates B19-NS1Exacerbated Liver Injuries in NZB/W F1 Mice. J Med Food 2017;20:56-64.

26. Cao X, Guo X, Yang X, et al. Transcriptional Responses and Gentiopicroside Biosynthesis in Methyl JasmonateTreated Gentiana macrophylla Seedlings. PLoS One 2016;11:e0166493.

27. Zhao L, Ye J, Wu GT, et al. Gentiopicroside prevents interleukin-1 beta induced inflammation response in rat articular chondrocyte. J Ethnopharmacol 2015;172:100-7.

28. Chen L, Liu JC, Zhang XN, et al. Down-regulation of NR2B receptors partially contributes to analgesic effects of Gentiopicroside in persistent inflammatory pain. Neuropharmacology 2008;54:1175-81.

29. Niu YT, Zhao YP, Jiao YF, et al. Protective effect of gentiopicroside against dextran sodium sulfate induced colitis in mice. Int Immunopharmacol 2016;39:16-22.

30. Lv J, Gu WL, Chen CX. Effect of gentiopicroside on experimental acute pancreatitis induced by retrograde injection of sodium taurocholate into the biliopancreatic duct in rats. Fitoterapia 2015;102:127-33.

31. Lin CY, Lee CH, Chang YW, et al. Pheophytin a inhibits inflammation via suppression of LPS-induced nitric oxide synthase-2, prostaglandin E2, and interleukin-1beta of macrophages. Int J Mol Sci 2014;15:22819-34.

32. Zenker S, Panteleev-Ivlev J, Wirtz S, et al. A key regulatory role for Vav1 in controlling lipopolysaccharide endotoxemia via macrophage-derived IL-6. J Immunol 2014;192:2830-6.

33. Awad AS, You H, Gao T, et al. Macrophage-derived tumor necrosis factor-alpha mediates diabetic renal injury. Kidney Int 2015;88:722-33.

34. Liu L, Zhao Y, Xie K, et al. Estrogen-induced nongenomic calcium signaling inhibits lipopolysaccharide-stimulated tumor necrosis factor alpha production in macrophages. PLoS One 2013;8:e83072.

35. Ehlting C, Ronkina N, Bohmer O, et al. Distinct functions of the mitogen-activated protein kinase-activated protein (MAPKAP) kinases MK2 and MK3: MK2 mediates lipopolysaccharide-induced signal transducers and activators of transcription 3 (STAT3) activation by preventing negative regulatory effects of MK3. J Biol Chem 2011;286:24113-24.

36. Austyn JM, Gordon S. F4/80, a monoclonal antibody directed specifically against the mouse macrophage. Eur J Immunol 1981;11:805-15.

37. Hume DA, Gordon S. Mononuclear phagocyte system of the mouse defined by immunohistochemical localization of antigen F4/80. Identification of resident macrophages in renal medullary and cortical interstitium and the juxtaglomerular complex. J Exp Med 1983;157:1704-9.

38. Hume DA, Halpin D, Charlton H, et al. The mononuclear phagocyte system of the mouse defined by immunohistochemical localization of antigen F4/80: macrophages of endocrine organs. Proc Natl Acad Sci U S A 1984;81:4174-7.

39. Lu M, Dai Y, Xu M, et al. The Attenuation of 14-3-3zeta is Involved in the Caffeic Acid-Blocked LipopolysaccharideStimulated Inflammatory Response in RAW264.7 Macrophages. Inflammation 2017;40:1753-60.

40. Udompong S, Mankhong S, Jaratjaroonphong J, et al. Involvement of p38 MAPK and ATF-2 signaling pathway in anti-inflammatory effect of a novel compound bis[(5-methyl)2-furyl](4-nitrophenyl)methane on lipopolysaccharide-stimulated macrophages. Int Immunopharmacol 2017;50:6-13.

41. Weng P, Zhang XT, Sheng Q, et al. Caveolin-1 scaffolding domain peptides enhance anti-inflammatory effect of heme oxygenase-1 through interrupting its interact with caveolin-1. Oncotarget 2017;8:40104-14.

Cite this article as: Wang Q, Zhou X, Yang L, Luo M, Han L, Lu Y, Shi Q, Wang Y, Liang Q. Gentiopicroside (GENT) protects against sepsis induced by lipopolysaccharide (LPS) through the NF- $\kappa \mathrm{B}$ signaling pathway. Ann Transl Med 2019;7(23):731. doi: 10.21037/atm.2019.11.126 